\title{
AVALIAÇÃO QUINQUENAL DO USO DA TERRA NA BACIA HIDROGRÁFICA DO CÓRREGO CERRADO/CADUNGA-MG ENTRE OS ANOS 2000 A 2015
}

\author{
Simone Marques Faria Lopes ${ }^{(\mathrm{a})}$; Dionys Fabrício Soares Franco ${ }^{(\mathrm{b})}$, João Batista Pereira Cabral ${ }^{(\mathrm{c})}$, \\ Carlos Eduardo Damasceno ${ }^{(\mathrm{d})}$.
}

(a) Curso de Geografia, Universidade Federal de Goiás/Regional Jataí, simoneufg@ yahoo.com.br

(b) Professor Me da rede Estadual de Ensino em Canápolis MG, dionys fabricio@ hotmail.com

(c) Curso de Geografia, Universidade Federal de Goiás/Regional Jataí, jbcabral@yahoo.com.br

(d) Graduando em Geografia, Universidade Federal de Goiás/Regional Jataí, eduardo.geo@ outlook.com.br

Eixo: Uso e ocupação das terras e legislação ambiental

\begin{abstract}
Resumo
Este trabalho centrou-se na avaliação temporal do uso e ocupação das terras da bacia do córrego Cerrado/Cadunga em Canápolis - MG, entre os anos de 2000, 2005, 2010 e 2015, buscando compreender as transformações antrópicas em termos de uso da terra. A escolha da bacia deu-se em virtude do uso múltiplo (atividades agrícolas, agropastoris e área urbana). O córrego apresenta maior concentração de áreas destinadas a agricultura, possuindo caráter agrícola. A antropização pode ser constatado pela degradação dos remanescentes de Cerrado, representado pela classe vegetação, a qual apresentou uma redução de 5,46\% de 2015 em relação ao ano 2000. Esta redução é considerada pequena, sendo justificada pelas políticas de reflorestamento apresentado em 2005 que aumentaram as áreas reflorestas em 39\%, e ainda, ao declínio do setor sucroalcooleiro em 2010, que agricultura cedeu lugar a pastagem voltando a apresentar declínio de $25 \%$ nas áreas de vegetação em relação a 2015.
\end{abstract}

Palavras chave: Avaliação espaço temporal; Modificação do espaço; Atividades agropastoris.

\section{Introdução}

A questão ambiental hoje, está inserida nos novos paradigmas da sociedade moderna, ocupando importante espaço nos cenários políticos, econômicos, sociais, científico e até mesmo cultural entre todas as nações, o qual herdou intensas mudanças no meio natural pela ação do homem, ao longo de todo processo histórico mundial.

Com o desenvolvimento tecnológico e o crescimento demográfico mundial, intensificou-se as atividades industriais, agrícolas, o extrativismo mineral e a urbanização, o que causou e vem causando modificações no espaço geográfico. Essas modificações em sua grande maioria são resultado de ações irracionais do uso 
e ocupação das terras e em consequência disso, observa-se que as alterações geraram um processo de desequilíbrio ambiental.

A ocupação antrópica das terras através de usos múltiplos indica a complexidade e dificuldade na elaboração de propostas para a gestão territorial, tanto em nível local como regional. O estudo de uso e ocupação da terra constitui-se uma ótima ferramenta para o planejamento da utilização racional dos recursos naturais, o qual pode contribuir na geração de informações para a avaliação da sustentabilidade ambiental, auxiliando planejadores e legisladores, pois ao verificar a utilização do solo em determinada área, pode-se elaborar uma melhor política de uso da terra para o desenvolvimento de uma dada região.

No Cerrado as modificações territoriais foram intensas principalmente no meio natural, em que grande parte dos recursos naturais foram utilizados de forma indiscriminada, resultados da expansão dos processos de agricultura e urbanização, consequentemente, a alteração do equilíbrio do meio natural, comprometendo a qualidade ambiental das bacias hidrográficas.

Sendo assim, diante deste cenário, o objetivo deste foi a avaliação temporal do uso e ocupação das terras da bacia hidrográfica do córrego Cerrado/Cadunga em Canápolis - MG, entre os anos de 2000, 2005, 2010 e 2015, buscando compreender as transformações antrópicas em termos de uso da terra. A escolha da bacia deu-se em virtude do uso múltiplo da bacia (atividades agrícolas, agropastoris e área urbana).

\section{Material e Métodos}

A bacia hidrográfica do córrego Cerrado/Cadunga situa-se na mesorregião do Triângulo Mineiro/Alto Paranaíba, microrregião de Uberlândia, no município de Canápolis, Estado de Minas Gerais (Figura 1) encontra-se entre as coordenadas geográficas, $18^{\circ} 43^{\prime} 29^{\prime \prime}$ de latitude Sul e $44^{\circ} 12^{\prime} 16^{\prime \prime}$ de longitude Oeste (IBGE, 2010). Sua bacia tem $137,7 \mathrm{~km}^{2}$ de extensão. 

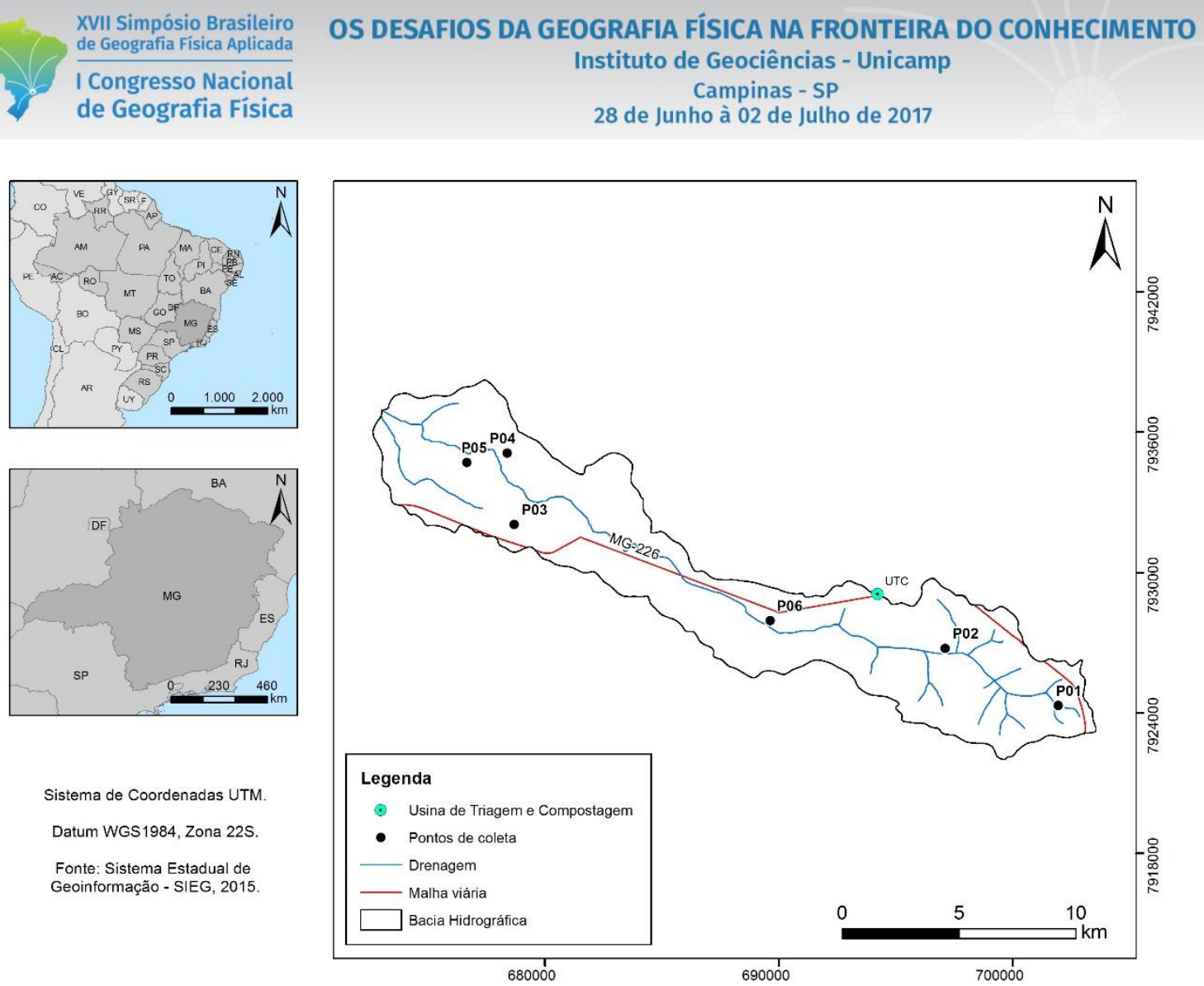

Figura 1- Localização da bacia hidrográfica do córrego Cerrado.

Org. Autores (2016)

Para a elaboração do trabalho foram aplicadas técnicas de sensoriamento remoto e geoprocessamento, para a delimitação da bacia hidrográfica do córrego Cerrado/Cadunga foram utilizadas imagens de satélite do Shuttle Radar TopographyMission - SRTM, com resolução espacial de 90 metros.

Para a confecção dos mapas de uso da terra de 2000, 2005 e 2010 e 2015 foram utilizadas imagens do sensor TM do satélite Landsat5 que estavam disponíveis no INPE (Instituto Nacional de Pesquisas Espaciais). Para o ano de 2015, devido a inoperância do Landsat5 a partir de 2011, utilizou-se Landsat 8, obtidas no U.S. GeologicalSurvey - USGS, EarthExplorer. Para a realização do mapeamento seguiu-se as etapas representadas no fluxograma (Figura 2). 


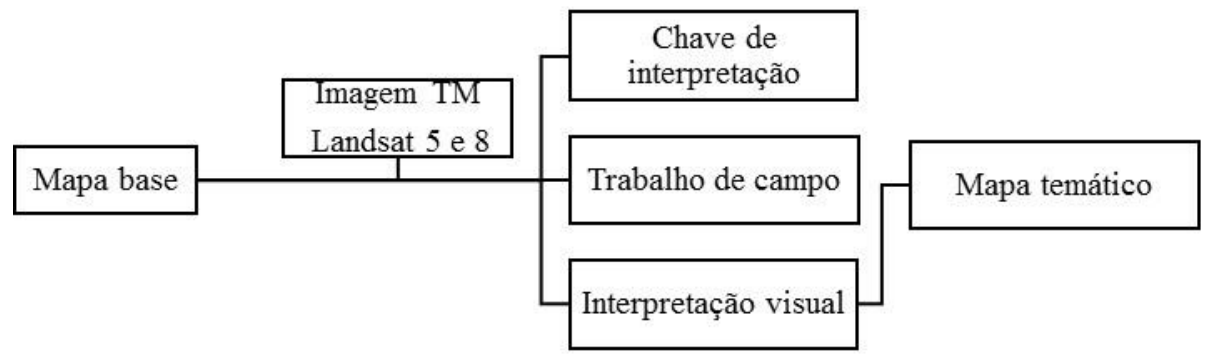

Figura 2- Fluxograma de execução do mapeamento do uso e ocupação.

Org. Autores (2016)

O processamento cartográfico de delimitação e caracterização do uso da terra foram realizados por meio do Software ArcGis 10.1 (EFL959692894). Utilizou se as imagens 23 de junho de 2000, do dia 05 de junho de 2005, 19 de junho de 2010 e 25 de fevereiro de 2015, (órbita 221, cenas 073), utilizando as bandas 5 R, 4 G, 3 B, para imagens Landsat 5 e as bandas 6 R, 5 G, 4 B, para Imagens Landsat 8.

Após o georreferenciamento, foi realizado a classificação não supervisionada no ArcGis 10.1, pela ferramenta "Multivariate/Isoclauster" que executa a agregação dos pixels semelhantes, formando as classes de uso em um arquivo matricial que posteriormente foi convertido em vetorial.

A correção dos polígonos ambíguos foram executados por meio do modulo "FildCalculator", ferramenta disponível no ArqGis 10.1. Para alteração dos atributos e reclassificação das respectivas classes, gerando o mapa temático final de uso da terra contendo as classes de uso, baseados na Chave de Interpretação de Rosa (2009), Água, Vegetação, Cultura, Pastagem e Solo descoberto, os quais foram validados com visita a campo.

\section{Resultados e discussão}

A bacia hidrográfica analisada foi a do Córrego Cerrado/Cadunga, localizada em Canápolis-MG, inserida na região do Cerrado Mineiro, um dos principais ecossistemas tropicais, e, segundo estimativas do Ministério do Meio Ambiente (2015), conta com menos de 20\% de sua área original preservada. Os modelos de uso da terra para os anos de 2000 e 2005 da bacia do córrego Cerrado/Cadunga são apresentados na figura 3 A e B. 

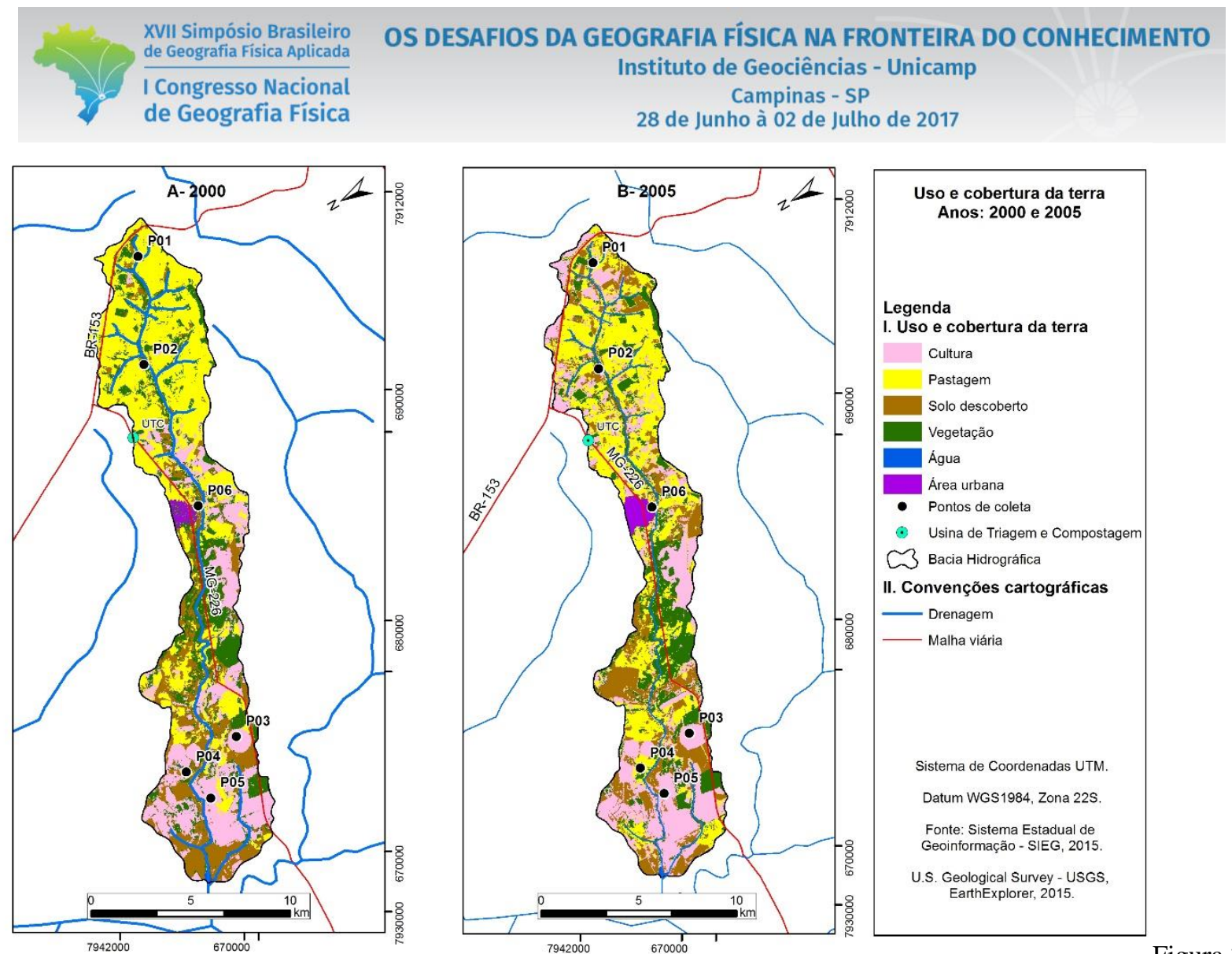

Uso da terra da bacia hidrográfica do córrego Cerrado/Cadunga para os anos de 2000 e 2005.

Org. Autores (2015)

O ano de 2000 apresentou 22,51\% para áreas de cultura, e 18,13\% de solos descobertos, totalizando 40,64\% de áreas destinas a agricultura. O ano de 2005 apresentou 28,41\% de áreas agricultáveis e ainda 17,98\% de solos expostos, o qual totalizou 46,39\% da área da bacia. Neste sentido verificou-se que o ano de 2005 exibiu acréscimo de $14,14 \%$ em relação ao ano de 2000, para áreas destinadas a culturas.

De acordo com Franco et al (2011) a cana-de-açúcar tornou-se a principal cultura do município a partir de 1990, por meio da instalação de empresas sulcroalcooleiras e sucroenergéticas na região. Ressaltando ainda que o histórico econômico e produtivo sempre esteve ligado a expansão canavieira no Estado de Minas Gerais. A própria adoção do nome Canápolis teve sua origem atrelado a cultura.

Franco et al., (2011, pág. 4) destacaram que a história econômica e produtiva do município de CanápolisMG sempre esteve interligada à expansão da cana-de-açúcar no Estado de Minas Gerais. "Para se ter uma ideia, o município de Canápolis teve um amplo crescimento desta monocultura na década de 90, chegando a ter mais de $25 \%$ de seu território ocupado por cana-de-açúcar”. E após 10 anos, houve a consolidação da cultura e a inserção da cultura do abacaxi, também com forte expressão.

A área urbana no ano de 2000 exibiu área de 0,82\% já em 2005, expandiu sua área cerca de 79,26\%, alcançando de 1,47\%. Constatou-se ainda decréscimo de 36,07\% nas áreas de pastagens de 2005 que ocupou 
24,77\% para o ano de 2000 que apresentou área de 38,74\%. Franco et al (2011) ressalta em suas pesquisas que a atividade pecuária foi a primeira a ser adotada na bacia do córrego Cerrado/Cadunga, o que ocasionou a retirada da vegetação nativa. Configurando assim um dos principais problemas ambientais decorrentes do uso e ocupação.

A classe vegetação, apresentou no ano de 2000 área correspondente a 19,58\% do território da bacia, no ano de 2005 área passou a ocupar 27,21\%, ou seja, apresentou acréscimo de 38,96\% em sua área. Este acréscimo pode ser justificado tanto pela redução das áreas de pastagens, quanto pelas políticas de desenvolvimento florestal do Estado. E ainda ao processo de reflorestamento da Companhia de Saneamento de Minas Gerais COPASA (FRANCO 2016).

No ano de 2010 (Figura 4A e B), a área de cultura ocupava para 17,52\%, diminuindo cerca de 38\% comparada ao ano de 2005. Mesmo somando as áreas com solos descobertos que ocuparam cerca de 20,71\%, cerca de $15 \%$ a mais que no ano 2005, a área que poderia ser destinada as atividades agrícolas da bacia $(38,69 \%)$, reduziu $16 \%$ em relação ao ano de 2005 . Tal redução justifica-se pelo aumento das áreas de pastagens, que chegou a ocupar 35,38\% da área total da bacia, cerca de $42 \%$ a mais que no ano de 2005 para pastagem.

A área de vegetação sofre uma redução de 9,26\% de sua área em relação ao ano de 2005, ocupando 24,69\% da bacia no ano de 2010. A redução é justificada pela abertura de novas áreas como o aumento das áreas de pastagens, para a utilização do curso d'água para a dessedentação dos animais. Fato também constatado por Franco et al. (2014) nos estudos realizados na bacia do Córrego Cerrado/Cadunga, o qual em visita à campo, observaram nas áreas de nascentes, a presença de animais dessedentando-se, cujo pisoteio pode agravar o processo de sulcos e erosões. 

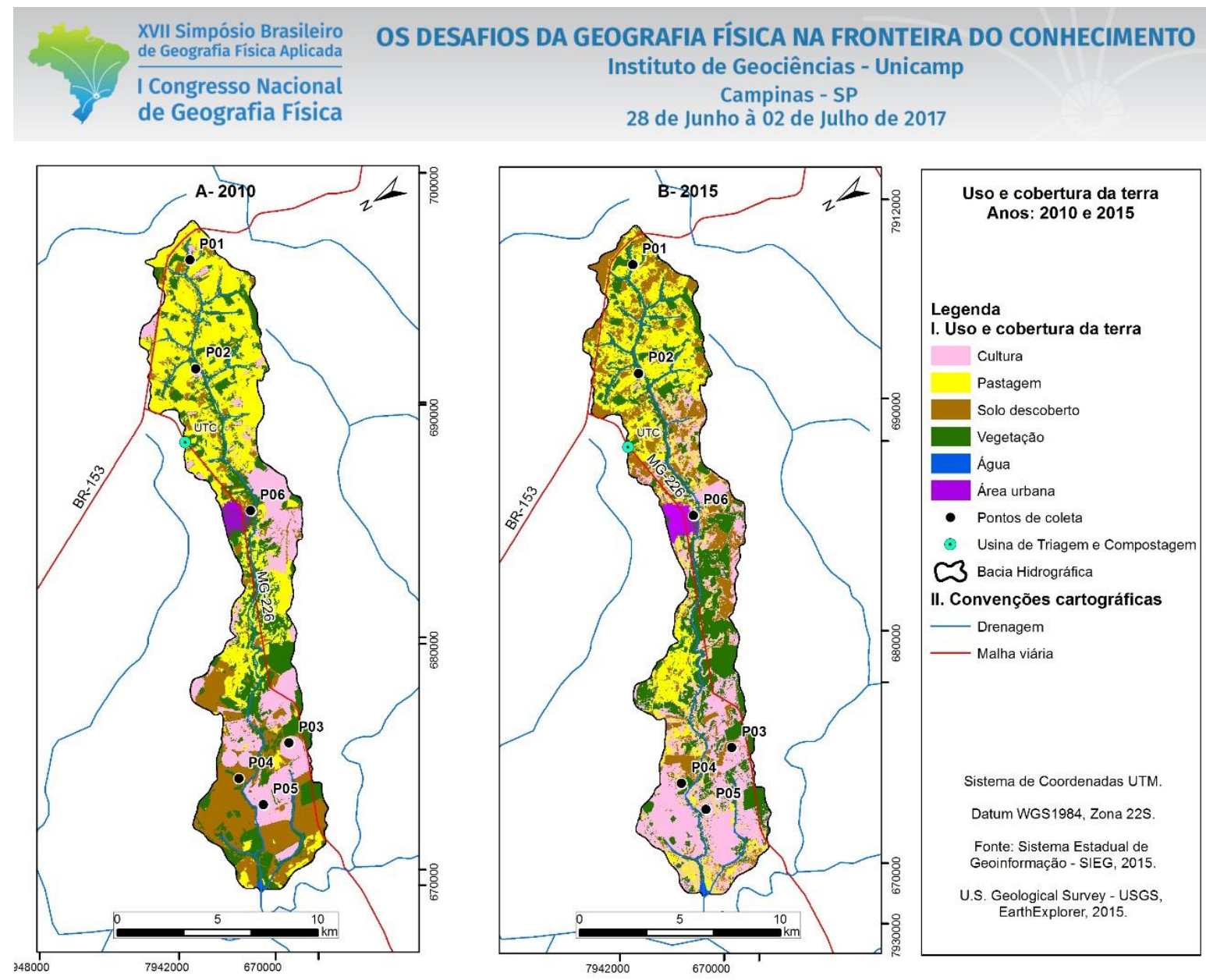

Figura 4- Uso da terra da bacia hidrográfica do córrego Cerrado/Cadunga para os anos de 2010 e 2015.

Org. Autores (2015)

Conforme observa-se na figura 5, além da utilização para dessedentação de animais o trechos nas margens dos cursos d'água, denominado Área de Preservação Permanente (APP), apresentaram se totalmente desprovidos de vegetação nativa representado no mapa pelo ponto 1 .

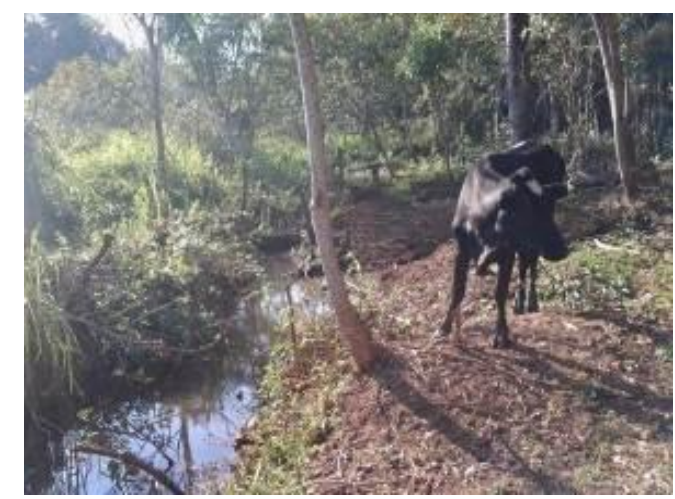

Figura 5- Utilização do córrego para a dessedentação de animais Fonte: Autores (2015).

De acordo com a classificação realizada no ano de 2010, pode-se constatar que a área urbana não apresentou crescimento significativo, passando de 1,47\% em 2005 para 1,48\% em 2010, cerca de $0,68 \%$ de crescimento. A classe água aumentou cerca de $37 \%$ em relação ao período de 2005 , ocupando $0,22 \%$ da área. O aumento 
pode ser justificado pelas condições climáticas do ano em questão, principalmente em relação ao nível do reservatório de Serra Dourada, à jusante da bacia.

O uso da terra referente ao ano de 2015, apresentou um aumento nas áreas de culturas, de 58,16\% em relação ao ano de 2010 ocupando 27,71\% da área, e, sofreu um decréscimo de 2,46\% em relação ao ano de 2005. Somando as áreas de cultura e solos descobertos, o ano de 2015 possui 48,05\% de sua área aptas as atividades agrícolas, o qual alcançou 59,60\% a mais que o ano de 2010, 4,0\% a mais que o ano de 2005 e ainda $18,72 \%$ mais que o ano de 2000.

Para o Jornal Cana (2015), o endividamento financeiro acumulado e o excesso de produção subsidiada de açúcar no mundo estão entre os principais fatores, juntamente com a crise financeira do país, que resultaram no fechamento de quatro usinas no Triângulo Mineiro e Alto Paranaíba, fato observado no município de Canápolis-MG e visível nos dados apresentados em relação ao ano de 2010. Segundo Franco et al. (2011), observa-se a mudança de cultivos, devido à uma crise no setor sucroenergético, fazendo com que as culturas de abacaxi (P02) soja (P03), milho (P04), sorgo (P05) e passem a ser as principais produzidas na bacia (Figura 6A a D). 


\section{A- Abacaxi}

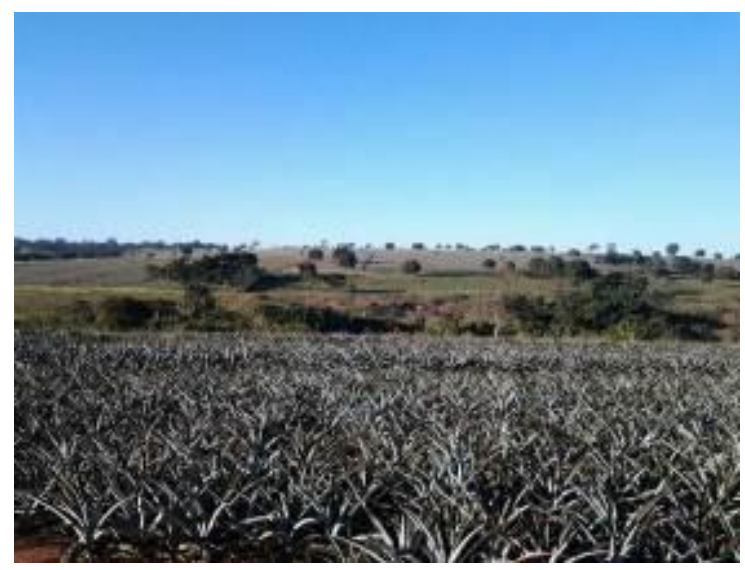

C- Milho

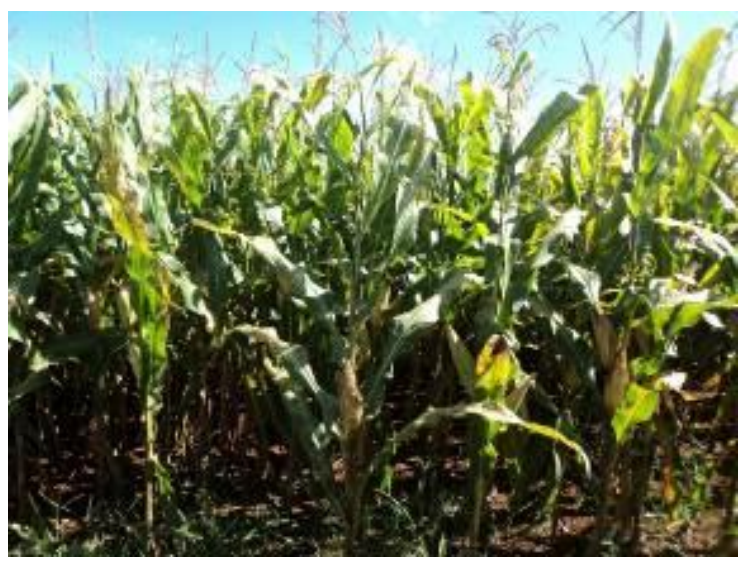

B- Soja

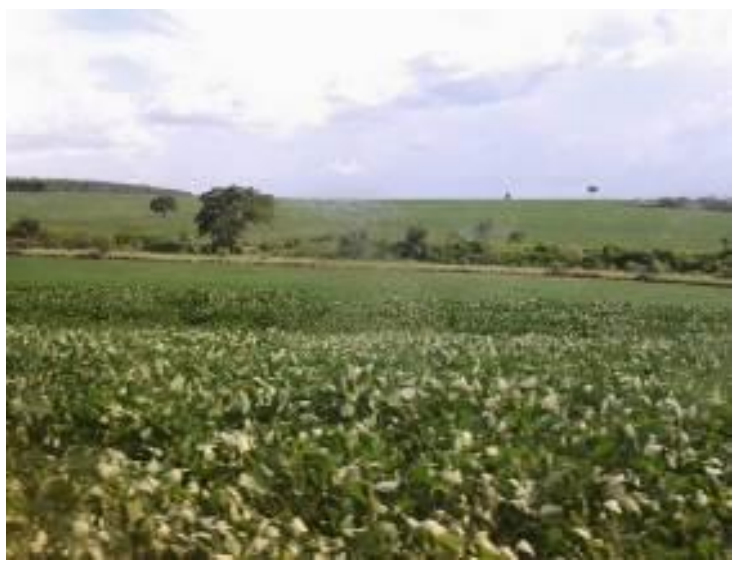

D- Sorgo

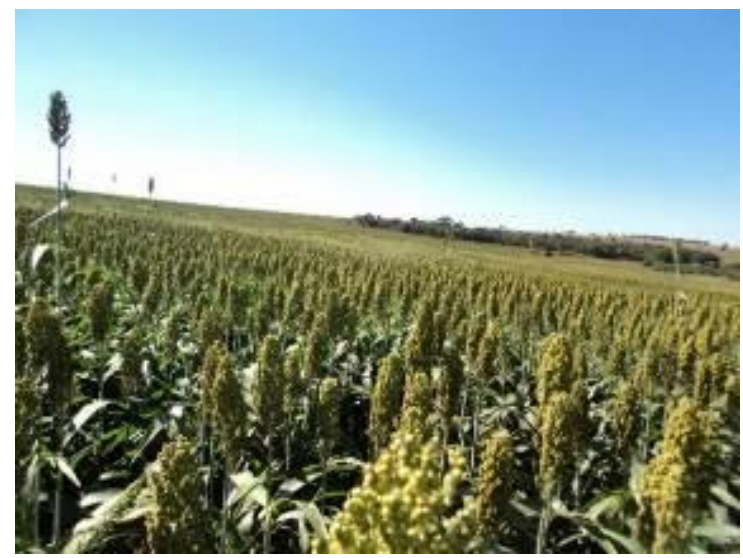

Figura 6- Principais culturas desenvolvidas na bacia do córrego Cerrado/Cadunga-MG. Fonte: Autores (2015)

A segunda maior classe de uso do solo do ano de 2015 foi a pastagem, ocupando cerca de 31,80\%, ou seja, $10 \%$ a menos que o ano de 2010, cuja diminuição justifica-se pelo aumento de outras culturas, como milho e soja. Outro fato relevante observado foi à redução da área de vegetação, que ocupava 18,51\% da área da bacia, ou seja, sofre uma redução de $25 \%$ em relação a 2010 e cerca de $31 \%$ em relação a 2005 e $18 \%$ em relação ao ano de 2000.

A classe água ocupava em 2015, 0,13\% da área da bacia, cerca de $40 \%$ a menos que no ano de 2010. Esta redução pode estar interligada ao volume de água no curso d'água, devido às características sazonais da região conforme observado em um açude dentro do perímetro da bacia, evidenciando ressecamento do solo (Figura 7). 


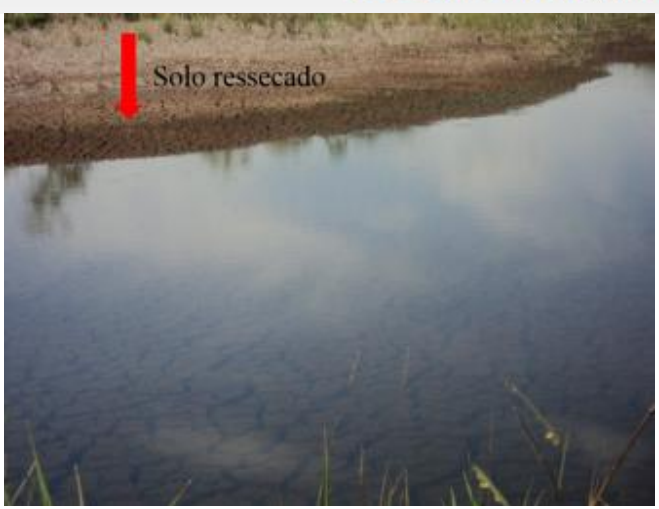

Figura 7- Mudança no nível da água em Açude da região.

Fonte: Autores (2016)

A área urbana apresentou aumento no ano de 2015, ocupando cerca de $1,51 \%$, com crescimento de 2,71\% considerado modesto para um período de 10 anos (Figura 8) sendo justificado pela construção de novos bairros, representado o P06 no mapa.

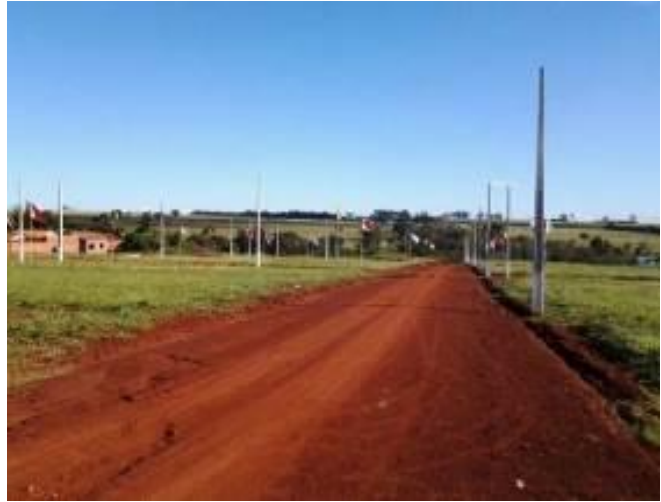

Figura 8- Loteamento em construção Canápolis-MG.

Fonte: Autores (2016)

Canápolis é um dos municípios em Minas Gerais que conta com uma usina de reciclagem de triagem e compostagem (UTC), inserida na referida bacia hidrográfica. A UTC está licenciada pelo COPAM/FEAM (Fundação Estadual de Meio Ambiente) desde o ano de 2000, servindo de modelo para várias outras cidades. Os materiais não recicláveis são depositados em valas e cobertos por terra, sem manta de proteção, e a compostagem é encaminhada para propriedades rurais para fins de adubação.

Constatou-se em visitas a campo o funcionamento parcial da usina. No ano de 2014 estava em funcionamento; porém em 2015, observou-se que a mesma estava fechada; funcionando de forma parcial como a área de depósito de resíduos urbanos e industriais, sem qualquer prevenção, igual a um "lixão".

A bacia do córrego Cerrado/Cadunga em função da ocupação antrópica, pode ser considerada agrícola considerando-se as áreas de cultura e solos descobertos. Outro fator relevante é o desmatamento das áreas de remanescentes de Cerrado, vegetação de extrema importância para a manutenção da biodiversidade e 


\section{OS DESAFIOS DA GEOGRAFIA FÍSICA NA FRONTEIRA DO CONHECIMENTO \\ Instituto de Geociências - Unicamp \\ Campinas - SP \\ 28 de Junho à 02 de Julho de 2017}

proteção dos solos, pois, além de realizar a fotossíntese, servindo como produtor primário produz oxigênio e celulose. Atua paralelamente na proteção do solo, pela capacidade de interceptar as chuvas, atenuando a incidência direta sobre os solos e interrompendo o carreamento de sedimentos, minimizando, assim, o efeito da erosão (GOMES, 2011).

As áreas de pastagens desde 2000 até 2015, ocupam a parte inicial da bacia, inserida sobre à Formação Vale do Rio do Peixe composta principalmente de arenitos. Verificou-se, também que em 2015, algumas áreas antes ocupadas por pastagens deram lugar à cultura do abacaxi; as demais áreas de agricultura ocorrem sobre a Formação Serra Geral, composta principalmente pelos Latossolos.

$\mathrm{Na}$ Tabela I consta a síntese das principais características do uso da terra referente as duas bacias objetos da presente pesquisa. O objetivo foi estabelecer as similaridades e diferenças entre os dois ambientes.

Tabela I- Principais Características do uso da terra e cobertura vegetal das bacias hidrográficas entre os anos de 2005 e 2015.

\begin{tabular}{lcccc}
\hline \multicolumn{5}{c}{ Córrego Cerrado/Cadunga - MG \% } \\
\hline Classe & $\mathbf{2 0 0 0}$ & $\mathbf{2 0 0 5}$ & $\mathbf{2 0 1 0}$ & $\mathbf{2 0 1 5}$ \\
\hline \multirow{4}{*}{ Cultura } & 22,51 & 28,41 & 17,52 & 27,71 \\
Solos descoberto & 18,13 & 17,98 & 20,71 & 20,34 \\
Pastagem & 38,74 & 24,77 & 35,38 & 31,80 \\
Vegetação & 19,58 & 27,21 & 24,69 & 18,51 \\
Água & 0,23 & 0,16 & 0,22 & 0,13 \\
Área Urbana & 0,82 & 1,47 & 1,48 & 1,51 \\
TOTAL & 100 & 100 & 100 & 100 \\
\hline \multicolumn{5}{l}{ Org. Autores (2016) }
\end{tabular}

Um aspecto relevante também a ser considerado é a presença da Usina de Triagem e Compostagem (inoperante em 2015), lixão e área urbana na bacia do córrego Cerrado/Cadunga, que gera preocupação no que tange à operação dos mesmos, pois, geralmente, as chuvas sobre as vertentes e consequente deflúvio superficial poderá carrear sedimentos e poluentes para a rede de drenagem.

\section{Considerações finais}

1- O córrego Cerrado/Cadunga apresenta maior concentração de áreas destinadas a agricultura, caracterizando a bacia como agrícola. 
OS DESAFIOS DA GEOGRAFIA FÍSICA NA FRONTEIRA DO CONHECIMENTO

Instituto de Geociências - Unicamp

Campinas - SP

28 de Junho à 02 de Julho de 2017

2- A antropização do córrego Cerrado/Cadunga, pode ser constatado pela degradação dos remanescentes de Cerrado, representado pela classe vegetação, a qual apresentou uma redução de 5,46\% de 2015 em relação ao ano de 2000. Esta redução é considerada pequena, sendo justificada pelas políticas de reflorestamento apresentado no ano de 2005 que aumentaram as áreas reflorestas em 39\%, e ainda, ao declínio do setor sucroalcooleiro no ano de 2010, que agricultura cedeu lugar a pastagem voltando a apresentar declínio de 25\% nas áreas de vegetação em relação a 2015.

3- A área urbana apresentou acréscimo de 84,14\% nos 15 anos de análise (2000 a 2015), visualizamos ainda que o ano de 2005 foi o que apresentou o maior ampliação na área urbana de 79,6\% para o período analisado.

\section{Bibliografia}

FRANCO. D. F.S. BATISTA. D.F. QUEIROZ. JUNIOR. V. S, SILVA, D. A. Análise geomorfológica preliminar do Córrego do Cerrado no município de Canápolis-MG. Revista GEONORTE, edição especial 4, v 10, n.1, p 81-86, 2014. Disponível em: <http://www.periodicos.ufam.edu.br/index.php/revista-geonorte/article/viewFile/1523/1406>. Acesso em: 08 ago. 2016.

FRANCO. D. F.S. REZENDE. M. SANTOS. J. C. dos. A evolução da monocultura canavieira no município de Canápolis/MG. In: ENCONTRO DE GEOGRAFIA DO PONTAL, 3 2011, Ituiutaba. Anais... Ituiutaba-MG , 2011.P 34

GOMES, D. D. M.. Geoprocessamento Aplicado a Análise da Vulnerabilidade à Erosão na Bacia Hidrográfica do Rio Jaibaras - Ceará. 2011. Dissertação de Mestrado (Programa de Pós-Graduação em Geologia) Universidade Federal do Ceará, Fortaleza - CE.

JORNAL CANA. Setor sucroenergético pede apoio contra a crise durante reunião em MG. Disponível em: http://www.jornalcana.com.br/setor-sucroenergetico-pede-apoio-contra-a-crise-durante-reuniao-em-mg/. 14/08/2015. Acesso em 08/10 de 2015.

MINISTÉRIO DO MEIO AMBIENTE - MMA Instituto Brasileiro do Meio Ambiente e Dos Recursos Naturais Renováveis - IBAMA. Monitoramento do desmatamento nos biomas brasileiros por satélite. Cerrado 2010-2011. Brasília 2015.

ROSA, R. Introdução ao sensoriamento remoto. $7^{\circ}$ ed., Uberlândia: EDUFU, 2009. 